\begin{tabular}{|l|c|c|c|c|}
\hline $\begin{array}{l}\text { Cuadernos de Investigación Geográfica } \\
\text { Geographical Research Letters }\end{array}$ & 2019 & N $^{\circ} 45(2)$ & pp. 661-685 & eISSN 1697-9540 \\
\hline
\end{tabular}

\title{
INFLUENCIA DE LA ACTIVIDAD PETROLERA Y LA GANADERÍA OVINA EN LA CUBIERTA DEL SUELO EN UNA REGIÓN ÁRIDA Y SEMIÁRIDA DE LA PATAGONIA ARGENTINA
}

\author{
M.A. BUZZI ${ }^{1 *}$, B.L. RUETER ${ }^{1}$, L. GHERMANDI ${ }^{2}$, F. MALDONADO ${ }^{3}$ \\ ${ }^{1}$ Departamento de Biología y Ambiente, Facultad de Ciencias Naturales y Ciencias de la Salud, \\ Universidad Nacional de la Patagonia San Juan Bosco, Ciudad universitaria Km 4, \\ 9000 Comodoro Rivadavia, Chubut, Argentina. \\ ${ }^{2}$ Laboratorio Ecotono, INIBIOMA (CONICET, Universidad Nacional del Comahue), \\ Bariloche, Río Negro, Argentina \\ ${ }^{3}$ Departamento de Química, Facultad de Ciencias Naturales y Ciencias de la Salud, \\ Universidad Nacional de la Patagonia San Juan Bosco, Argentina.
}

RESUMEN. La Geografía como ciencia ha provisto el mayor cuerpo teórico para el estudio de las configuraciones que se producen sobre el espacio geográfico. La generación de cartografía que representa las cubiertas de suelo es uno de los usos más importantes de la percepción remota. Se seleccionaron polígonos, con actividad petrolera y ganadera, en las siguientes unidades de paisaje: cañadones, pampas y valles. Los poligonos se utilizaron para evaluar cambios multi-temporales de las cubiertas de suelo y las comunidades vegetales en un período de 15 años. Se realizaron clasificaciones supervisadas y análisis de métricas de paisaje para examinar las posibles causas de estos cambios comparando: i) polígonos sin actividad petrolera ni ganadera (testigo), ii) con actividad petrolera y ganadera, iii) con actividad petrolera y sin actividad ganadera, y iv) sin actividad petrolera y con actividad ganadera. Los resultados obtenidos indicaron que la densidad de parches, el borde total, la densidad de borde y el índice de división de los fragmentos aumentaron en las tres unidades de paisaje, entre 2001 y 2016. El indice de contagio, en cambio, disminuyó. Se observó un incremento del suelo desnudo en las pampas y en los valles occidentales, con un retroceso de las comunidades vegetales dominantes. La densidad de parches en los sitios sin disturbios fue la menor, y en los sitios con ambos disturbios actuando simultáneamente fue máxima. En los sitios sin disturbio el tamaño efectivo de malla fue máximo, mientras que en los sitios con algún disturbio fue menor. Al analizar el efecto del disturbio sobre los elementos del paisaje se observó que su presencia genera la mayor densidad de parches y la mínima conectividad. Los resultados muestran que se produjo un proceso de fragmentación en las coberturas del suelo direccionados por la explotación petrolera y la ganadería ovina, que disminuyen el tamaño de los parches y, por lo tanto, la densidad de los mismos por unidad de superficie. 


\title{
Influence of oil activity and sheep ranching on plant cover in the arid and semi- arid region of Patagonia, Argentina
}

\begin{abstract}
The Geography has provided the greatest theoretical body for the study of the configurations that occur over the geographical space. The generation of cartography that represents ground cover is one of the most important uses of remote sensing. Polygons were selected, with oil and livestock activity, in the landscape units: coastal canyons, plateaus and western valleys. The polygons were used to evaluate multi-temporal changes in land cover and plant communities over a period of 15 years. Supervised classifications and analysis of landscape metrics were made to examine the possible causes of these changes by comparing: i) polygons without oil or livestock activity (control), ii) polygons with oil and livestock activity, iii) polygons with oil activity and without livestock activity, and iv) polygons without oil activity and livestock activity. The results obtained indicated that the density of patches, the total edge, the edge density and the division index of the fragments increased in the three landscape units, between 2001 and 2016. The contagion index, however, decreased. An increase in bare soil was observed in the plateaus and in the western valleys, with a regression of the dominant plant communities. The density of patches in the sites without disturbance was the lowest, and in the sites with both disturbances acting simultaneously was maximum. In the sites without disturbance the effective mesh size was maximum, while in the sites with some disturbance it was smaller. When analyzing the effect of the disturbance on the elements of the landscape it was observed that the presence of the disturbance generates the highest density of patches and the minimum connectivity. The results show that there was a process of fragmentation in the coverage of the soil directed by the oil exploitation and sheep farming, which decrease the size of the patches and, therefore, the density of the same per unit area.
\end{abstract}

Palabras claves: zonas áridas, fragmentación, métricas de paisaje, explotación petrolera, ganadería ovina.

Key words: arid zones, fragmentation, landscape metrics, oil exploitation, sheep farming.

Recibido: 16 de junio de 2018

Aceptado: 27 de noviembre de 2018

*Correspondencia: M. A. Buzzi, Departamento de Biología y Ambiente, Facultad de Ciencias Naturales y Ciencias de la Salud, Universidad Nacional de la Patagonia San Juan Bosco, Ciudad universitaria Km 4, 9000 Comodoro, Argentina. E-mail: marianabuzzi86@gmail.com

\section{Introducción}

La Geografía dispone del mayor cuerpo teórico para el estudio de las configuraciones que se producen sobre el espacio geográfico (Buzai y Mendoza, 2004). La cartografía es una rama de la Geografía que permite la generación de mapas que representan las 
cubiertas de suelo. La cartografía realizada a partir del procesado de imágenes de satélite es uno de los usos más importantes de la percepción remota (Martinez del Castillo et al., 2015), principalmente cuando las imágenes de satélite provienen de la serie Landsat (Mohammady et al., 2015). Se define a la cubierta de suelo por el material que lo compone, el cual puede ser suelo desnudo, comunidades vegetales, agua, asfalto, entre otros tipos de cubiertas (Fisher y Unwin, 2005). Según la resolución del sensor, el número de clases de cubierta que se pueden identificar en la imagen varía. Para determinar los componentes que caracterizan la cubierta del suelo se utilizan algoritmos de clasificación de imágenes de satélite a partir de los cuales se obtiene la cartografía y el inventario de las clases objeto de estudio y se generan los mapas temáticos (Chuvieco, 2010).

En la ecología de paisaje se utilizan métodos cuantitativos para evaluar la composición del paisaje y los servicios ecosistémicos (Syrbe y Walz, 2012). La metodología más utilizada es a través de métricas de paisaje, que son indicadores de los procesos de transformación que se dan en el paisaje y proveen información valiosa que permite caracterizar los cambios que se producen en el paisaje (Shooshtari et al., 2018). Estas métricas pueden verse afectadas por la relación recíproca entre los factores físicos de los patrones del paisaje y los procesos económicos (Li y Wu, 2004). Están influidos por varios factores bióticos, abióticos y ecológicos, tales como la precipitación anual, la temperatura, el suelo y las actividades humanas (Uuemaa et al., 2013).

En el área de estudio, las principales fuerzas directrices que producen cambios en las cubiertas de suelo son el pastoreo ovino y la explotación petrolera. El primero es uno de los usos del suelo más extendidos a nivel mundial (Fleischner, 1994; Alkemade et al., 2013) y una de las actividades más importantes que afectan a las comunidades vegetales y animales, así como también a la función de los ecosistemas (Eldridge et al., 2016). La región patagónica se caracteriza por tener una de las mayores extensiones de pastizal en el mundo. Allí conviven grandes herbívoros nativos, como Lama guanicoe (guanaco) y Rhea pennata (choique), con el ganado principalmente ovino, introducido a principios del siglo XX. El manejo del ganado es extensivo, organizado en estancias de entre 10.000 y 50.000 ha (Ares et al., 2003) y es una de las principales actividades económicas de la región. Los efectos del pastoreo en las comunidades vegetales dependen del tipo de herbívoro, el régimen de pastoreo, y de los procesos y atributos de los ecosistemas analizados (Eldridge et al., 2016).

La industria petrolera, en sus etapas de exploración, explotación y transporte, genera caminos, locaciones (área preparada para la instalación de torres de perforación), áreas de maniobras de maquinaria y oleoductos. Por eso produce parches de disturbio severo, aunque puntuales. A éstos se unen disturbios de tipo lineal (caminos de prospección sísmica y otros caminos), en los cuales la cubierta vegetal es removida completamente y el suelo es compactado (Paruelo y Aguiar, 2003). La actividad petrolera genera fragmentación en el paisaje que contrasta fuertemente con los sectores aledaños (Li et al., 2008; Wang et al., 2005).

Las consecuencias de la fragmentación del hábitat han sido estudiadas en el marco de la teoría de biogeografía de islas (MacArthur y Wilson, 1967), que extrapola el concepto de insularidad a elementos del paisaje. Esta teoría revolucionó el campo de la biogeografía y sigue despertando un gran interés (Harrison et al., 2006; Losos y Ricklefs, 2010). En general, la mayoría de los paisajes fragmentados en el mundo real no se ajustan a la 
concepción binaria de "hábitat" y "no-hábitat" que propone el modelo de MacArthur y Wilson (1967) en los que las transiciones entre los diferentes elementos del paisaje se definen como abruptas, y la influencia de la matriz es ignorada. Recientemente, se ha presentado una visión alternativa llamada modelos de paisaje continuo (continuous landscape approaches) (Manning et al., 2004). Este modelo propone que la respuesta de los organismos a la fragmentación estaría determinada por un gradiente continuo, lo cual permite distinguir los efectos separados de la disponibilidad del hábitat, el aislamiento y el efecto borde (Manning et al., 2004; Fischer y Lindenmayer, 2006, 2007). El padre de la ecología del paisaje (Forman, 1995) basó su modelo de parche-matriz-corredor en una visión intermedia entre la teoría de biogeografía de isla (MacArthur y Wilson, 1967) y el modelo de paisaje continuo (Manning et al., 2004). El modelo de parche-matriz-corredor define a los parches como áreas de hábitat discretas de diferentes tamaños y forma. Los parches pueden tener un microambiente en el centro del mismo diferente al de su periferia. Esto produce el efecto borde con una composición florística y abundancia de especies diferentes. Este efecto incrementa la riqueza específica del parche a partir del flujo de nutrientes y energía desde la matriz (Forman y Godron, 1981). Los corredores son los elementos lineales del paisaje que conectan parches, ambos están embebidos en la matriz que puede tener distinta extensión (Valdés y García, 2009). Este modelo ha sido utilizado para analizar la fragmentación del paisaje en ambientes modificados por la agricultura (Herrera y Laterra, 2007, 2011; Fahrig et al., 2011), en áreas boscosas (Pincheira-Ulbrich et al., 2009) y en ambientes áridos y semiáridos (Maestre y Cortina, 2004).

El objetivo general de este trabajo es analizar multi-temporalmente las cubiertas de suelo y analizar los procesos de fragmentación producidos por la ganadería ovina extensiva y la industria petrolera en la región árida y semiárida de la Patagonia. Los objetivos específicos incluyen: a) evaluar los cambios en las cubiertas de suelo sucedidos en 15 años de actividad ganadera y petrolera en tres unidades de paisaje, b) analizar la dinámica de las comunidades vegetales, y c) examinar las posibles causas de estos cambios, considerando las dos aciones separadamente y en conjunto.

Se plantea la siguiente hipótesis de trabajo: los cambios en las cubiertas de suelo provocados por la ganadería ovina extensiva y la industria petrolera originan fragmentación y pérdida de conectividad, en las unidades de paisaje de la región árida y semiárida de la Patagonia Argentina.

\section{Materiales y Métodos}

\section{1. Área de estudio}

El área de estudio se encuentra en la cuenca del Golfo San Jorge. Representa más del $30 \%$ de las reservas patagónicas de hidrocarburos y está ubicada en la zona central de la Patagonia Argentina, cubriendo una superficie aproximada de $170.000 \mathrm{~km}^{2}$ (Fig. 1). La ciudad más importante de la región es Comodoro Rivadavia, con 186.583 habitantes (INDEC, 2010). El área de estudio se divide en tres unidades de paisaje que, de oeste a este, son: los valles, las pampas y los cañadones (Buzzi et al., 2013). Los valles ocupan una superficie de $532 \mathrm{~km}^{2}$ y se encuentran en la unidad fitogeográfica del Distrito Central, Subdistrito 
Chubutense (León et al., 1998), siendo la unidad más extendida de Patagonia central. La Pampa tiene una superficie de $628 \mathrm{~km}^{2}$. Las principales unidades son: Pampa del Castillo y Pampa Salamanca, con una altitud promedio de aproximadamente $750 \mathrm{~m}$ s.n.m. Posee orientación suroeste-noreste, desde donde se originan numerosos cañones fluviales en dirección hacia el océano Atlántico (Rueter, 2013). Los cañadones tienen una superficie aproximada de $300 \mathrm{~km}^{2}$. El límite oriental corresponde a la línea del supra-mareal, sobre el golfo San Jorge (Mar Argentino); el límite norte y oeste es el nivel máximo de las pampas del Castillo y Salamanca; y el límite sur se encuentra a los $45^{\circ} 48^{\prime}$ de latitud sur.

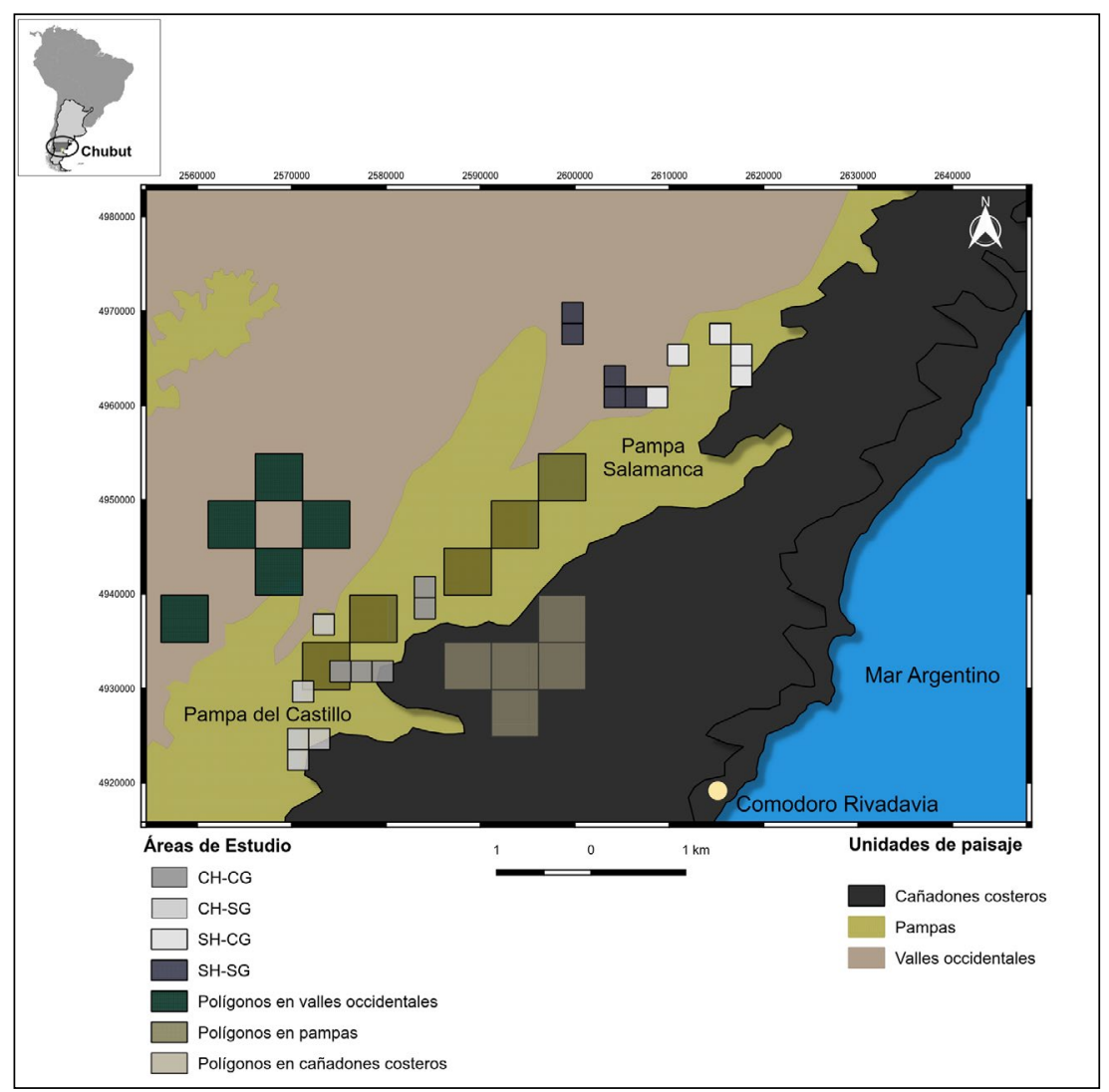

Figura 1. Área de estudio.

\subsection{Características de las imágenes satelitales}

Se utilizaron imágenes provistas por el satélite Landsat 7 Enhaced Thematic Mapper Plus (ETM+), correspondientes al 14 de septiembre de 2001 e imágenes del satélite Landsat 8 Opertational Land Imager (OLI) del 30 de agosto de 2016. El path y row corresponden al 229 y 092, respectivamente. Se seleccionaron estas fechas por su coincidencia con la estación 
de crecimiento de la vegetación y presentar una precipitación estacional y anual similar. Esto facilita la identificación de los estratos de la vegetación en función de su respuesta espectral. Estas imágenes, bajo el sistema de procesamiento 1-A (corrección geométrica en el sistema UTM y proyección WGS 84), fueron obtenidas a través del United States Geological Survey (USGS). Las imágenes fueron combinadas para la realización de una representación en falso color compuesto para resaltar las características de la vegetación.

\subsection{Pre-procesamiento de las imágenes Landsat}

Se realizó un pre-procesamiento de las imágenes de satélite que consistió en una calibración radiométrica que convierte los niveles digitales a unidades físicas como la reflectancia Top of Atmosphere (TOA), específica para cada sensor. Este procedimiento se lleva a cabo conociendo la información acerca de los parámetros de calibración de los sensores (Lmin y Lmax) disponibles en las cabeceras de las imágenes (Paruelo et al., 2004). La calibración se realizó con el complemento denominado Semi-Automatic Classification Plugin (Congedo, 2016) del programa QGIS v. 2.18. El complemento centra su corrección atmosférica en el método de sustracción de objeto oscuro (DOS 1), que se basa en el supuesto en que dentro de la imagen algunos píxeles están en completa sombra y sus radiancias son debidas a la dispersión atmosférica. Esta suposición se combina con el hecho de que muy pocos objetos en la superficie de la Tierra son absolutamente negros, por lo que una reflectancia mínima de un $1 \%$ es mejor que $0 \%$. Suponiendo la existencia de objetos oscuros (reflectancia superficial $\approx 0$ ), el valor mínimo de nivel digital se resta al de todos los píxeles, eliminando los efectos atmosféricos en toda la imagen (Chávez, 1996). Posteriormente se elaboró una combinación con las bandas que permiten la formación de un falso color compuesto. La metodología aplicada se resume en la Fig. 2.

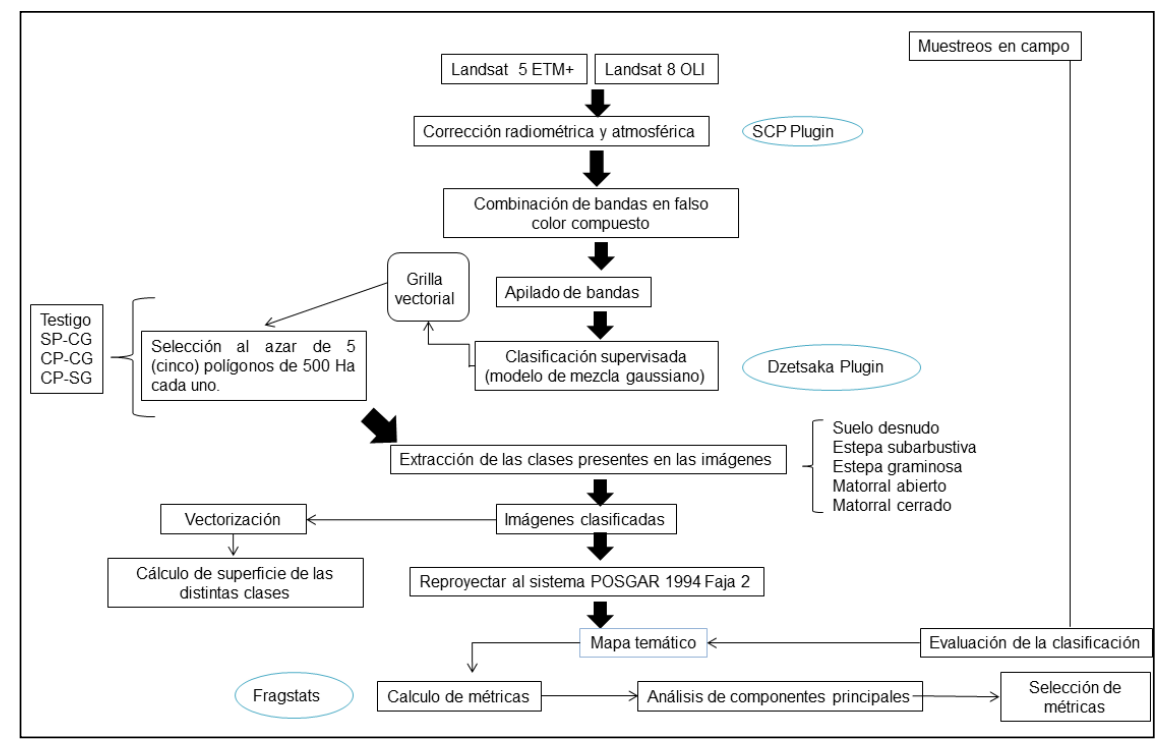

Figura 2. Resumen de la metodología aplicada para elaborar los mapas temáticos. 


\subsection{Diseño del muestreo}

Se seleccionaron al azar cinco polígonos de 2500 ha en cada una de las unidades de paisaje: cañadones, pampas y valles occidentales. Este muestreo se ubicó en áreas con actividad petrolera y ganadera ovina extensiva con cargas representativas de la región (Buzzi et al., 2017). Los polígonos se utilizaron para evaluar los cambios multi-temporales de las cubiertas de suelo y la dinámica de las comunidades vegetales en un período de 15 años. La selección de estos sitios se basó en antecedentes sobre los usos de suelo en las diferentes áreas. Para examinar las posibles causas de estos cambios, considerando los disturbios independientemente y en conjunto, se analizaron diferentes escenarios de explotación de los recursos naturales; estos corresponden con las características de las cubiertas de suelo de cada una de las áreas. Los escenarios son los siguientes: i) sin actividad petrolera ni ganadera (testigo), ii) con actividad petrolera y ganadera (CP-CG), iii) con actividad petrolera y sin actividad ganadera (CP-SG), y iv) sin actividad petrolera y con actividad ganadera (SP-CG). En cada escenario se seleccionaron cinco polígonos al azar con una superficie de 500 ha cada uno (Fig. 1).

\subsection{Clasificación supervisada}

La clasificación de imágenes se divide en no supervisada y supervisada (Chuvieco, 2010). Esta última fue utilizada en este trabajo y requiere que el operador explicite las clases a definir (Olaya, 2014). El procedimiento consiste en la categorización de áreas representativas de cada clase sobre una imagen multibanda en la que se reemplazan los niveles digitales por tipos de cubierta. Estas clases representativas se denominan áreas de entrenamiento. Para poder llevar esto a cabo es necesario el conocimiento del área de estudio, lo que permite la selección correcta de las áreas de entrenamiento que se utilizarán como base para clasificar el resto de la imagen (Richards y Jia, 2006). Se utilizó el algoritmo de máxima similitud, que utiliza el umbral gaussiano almacenado en cada firma espectral, para asignarle a cada pixel una determinada clase (Huang et al., 2009). La clasificación supervisada se llevó a cabo en los polígonos de 2500 ha y de 500 ha, con el complemento Dzetsaka plugin del programa QGIS (Zhao et al., 2016). Las imágenes clasificadas fueron re-proyectadas al sistema nacional denominado POSGAR 1994 faja 2. Estos mapas temáticos se utilizaron como input del Fragstats v.2.1 para realizar el cálculo de las métricas de paisaje (McGarigal et al., 2015).

\subsection{Validación de las clasificaciones}

Se trabajó en 39 sitios, ubicados en áreas con actividad petrolera y ganadería ovina extensiva con cargas representativas de la región, en los cañadones, pampas y valles (Fig. 3). Se utilizaron parcelas de 1 ha (100 x 100 m) ubicadas en áreas de homogeneidad vegetal para garantizar que la parcela muestreada sea representativa de la clase espectral provista por el sensor (Buzzi et al., 2017). Con el fin de evaluar la fidelidad de las clasificaciones, se usó una matriz de confusión, generada a través de la comparación entre los datos de campo y las clasificaciones supervisadas. 


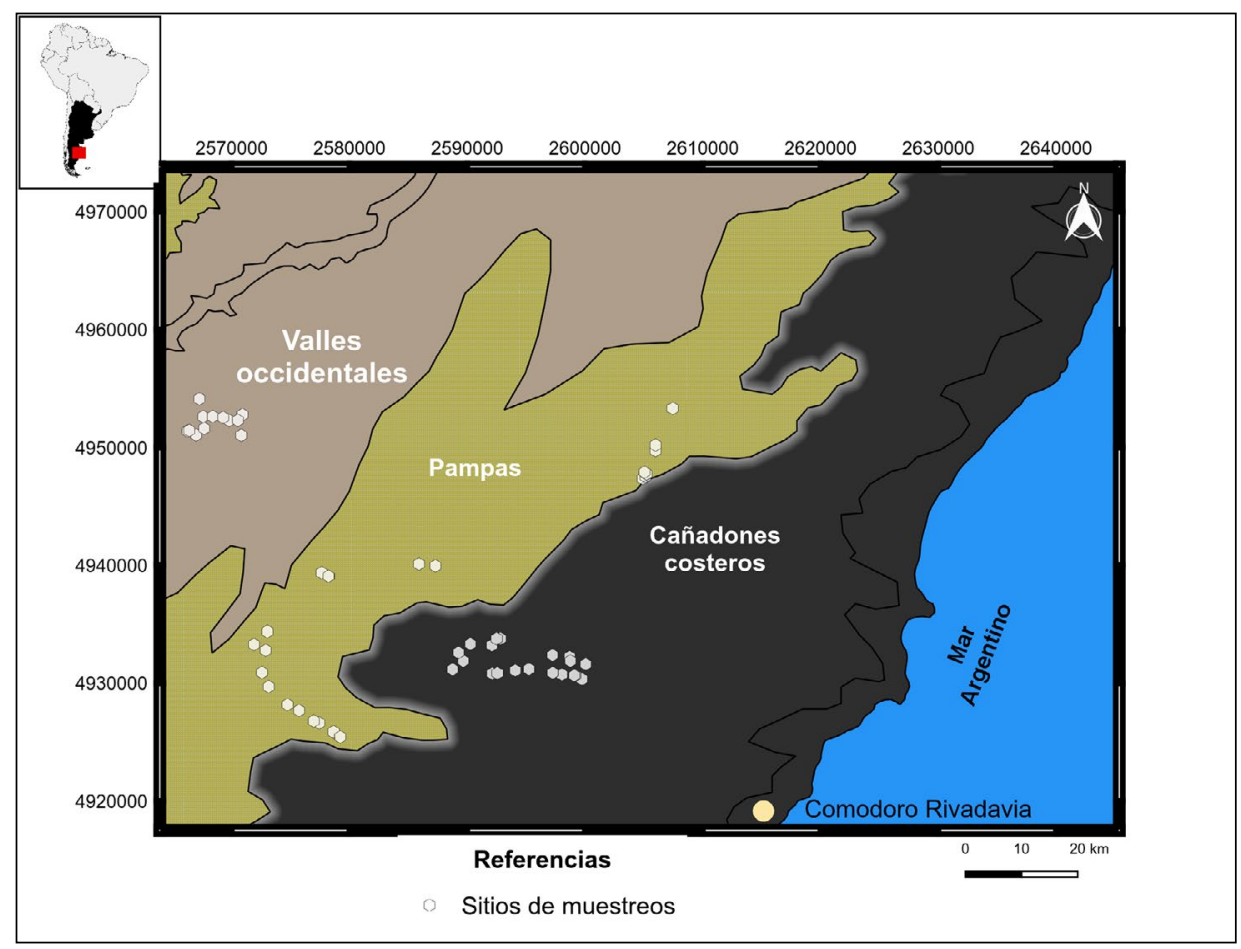

Figura 3. Sitios de muestreos utilizados para la validación de las clasificaciones supervisadas.

La precisión del producto es la probabilidad de que un pixel de referencia sea clasificado correctamente, es decir es una medida del error de omisión, mientras que la precisión del usuario es la probabilidad de que un pixel clasificado represente realmente la clase de cubierta del suelo (Keles et al., 2008). Se calcularon los coeficientes de Kappa que son utilizados para medir la precisión de la clasificación (Foody, 2002; Lu et al., 2008).

\subsection{Métricas de paisaje}

El cálculo de las métricas de paisaje se realizó con el programa Fragstats v.2.1 (McGarigal et al., 2015). La cartografía utilizada como input para el cálculo de las métricas fue proporcionada por las imágenes clasificadas en función de los estratos que conforman la vegetación de la región. Las métricas de paisaje fueron computadas utilizando la regla de cuatro celdas con el vecino más cercano. Se realizó el análisis de componentes principales (PCA) para seleccionar el paquete mínimo de métricas que represente mejor la variabilidad espacial y temporal del paisaje. McGarigal et al. (2015) describieron las fórmulas por cada una de las métricas empleadas para el PCA, las cuales están descritas en la Tabla 1. 


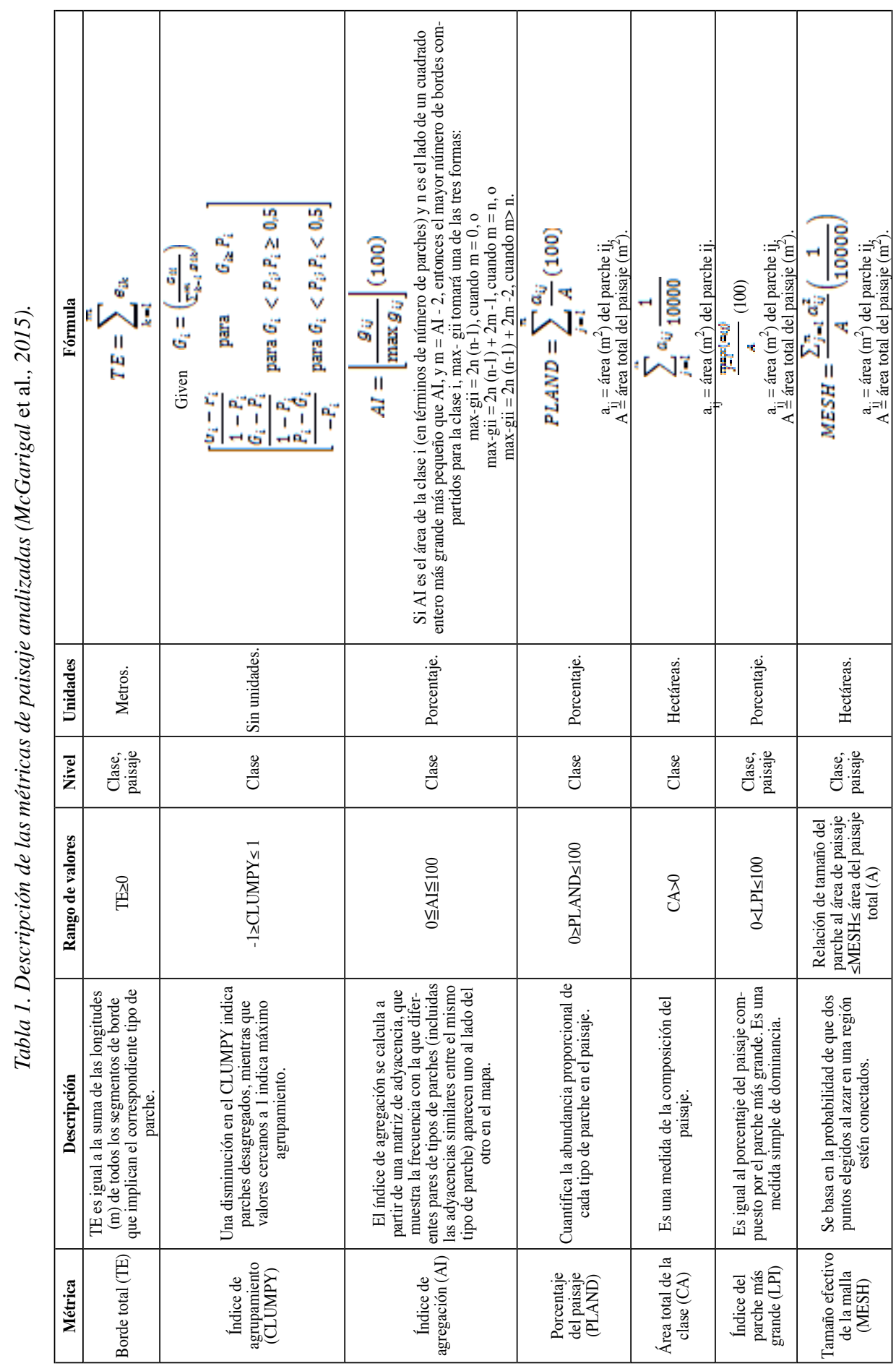




\begin{tabular}{|c|c|c|c|c|c|c|c|c|c|c|}
\hline & 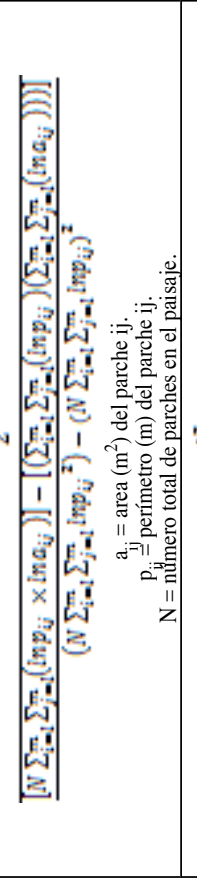 & 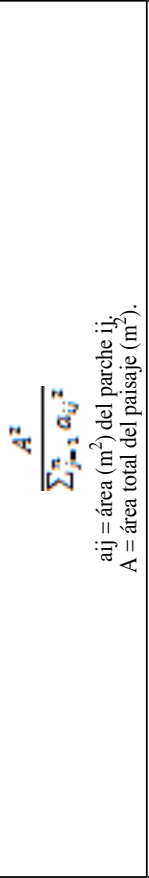 & 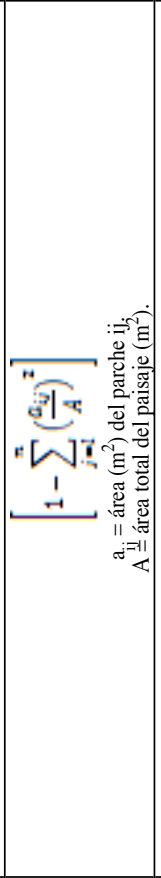 & 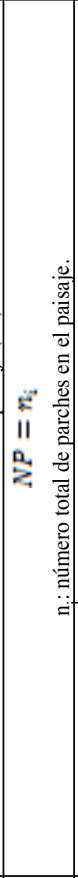 & 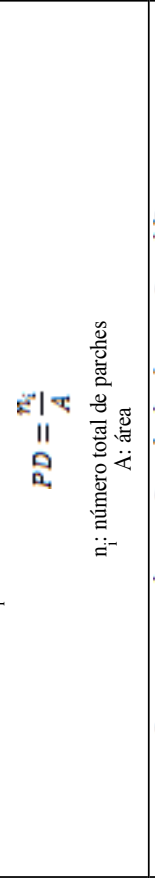 & 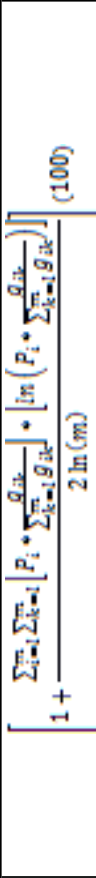 & 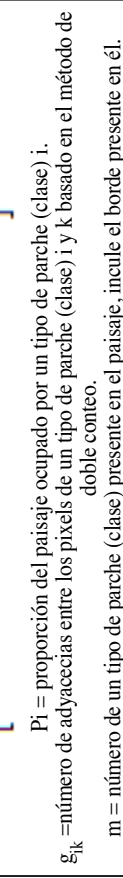 & 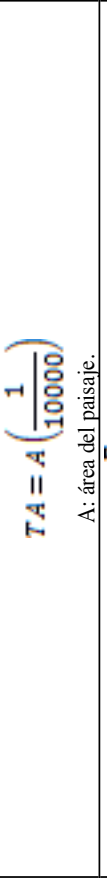 & 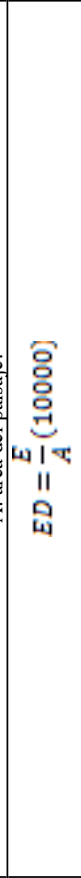 & 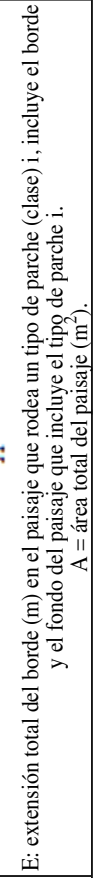 \\
\hline 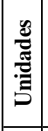 & 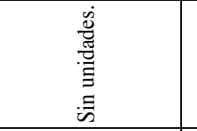 & 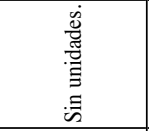 & 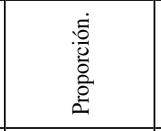 & 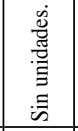 & 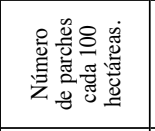 & & : & 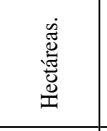 & & 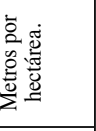 \\
\hline$\overline{\bar{z}}$ & 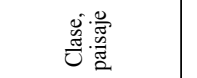 & 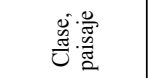 & 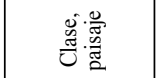 & 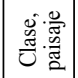 & 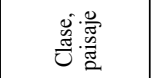 & & 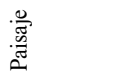 & 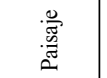 & & 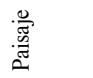 \\
\hline 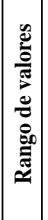 & 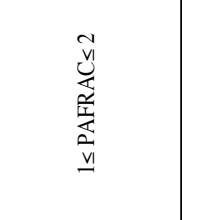 & 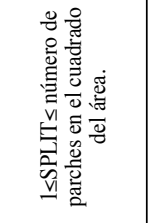 & 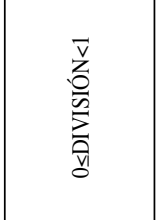 & $\overline{\mathrm{N}}$ & 㑒 & & 8 & 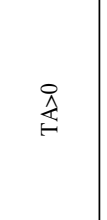 & & 全 \\
\hline 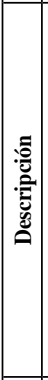 & 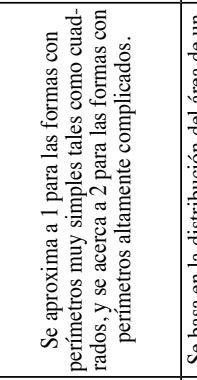 & 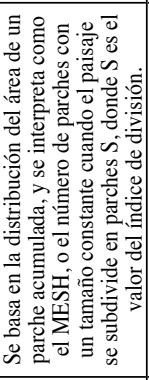 & 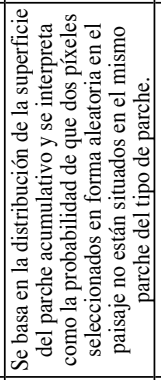 & 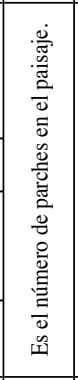 & 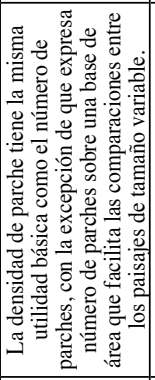 & 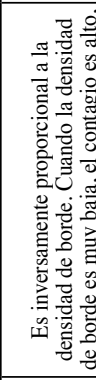 & 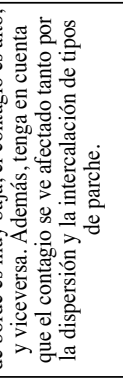 & 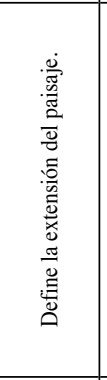 & & 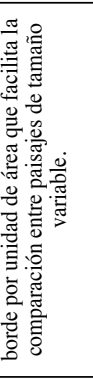 \\
\hline 离 & 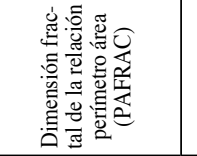 & 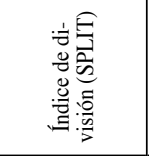 & 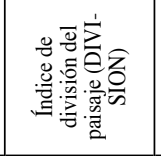 & 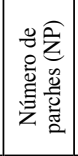 & 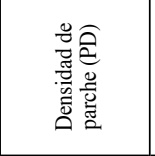 & & & 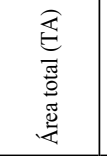 & & 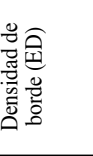 \\
\hline
\end{tabular}




\subsection{Análisis estadístico}

Se realizó la prueba de Shapiro-Wilk (1965) para evaluar si las métricas de paisaje estudiadas siguen el modelo normal de distribución de probabilidades. En los casos en que la distribución no fue normal, se optó por utilizar pruebas no paramétricas, específicamente el test de Wilcoxon (1945). Los análisis estadísticos se realizaron con el programa Statistica v.7.

\section{Resultados}

\subsection{Cambios en las cubiertas de suelo}

Los coeficientes Kappa de las clasificaciones supervisadas fueron superiores a 0,80 en todos los casos (Tabla 2).

Tabla 2. Matriz de confusión (expresada en porcentajes).

\begin{tabular}{|l|c|c|c|c|c|}
\hline & $\begin{array}{c}\text { Suelo } \\
\text { desnudo }\end{array}$ & $\begin{array}{c}\text { Estepa } \\
\text { subarbustiva }\end{array}$ & $\begin{array}{c}\text { Estepa } \\
\text { graminosa }\end{array}$ & $\begin{array}{c}\text { Matorral } \\
\text { abierto }\end{array}$ & $\begin{array}{c}\text { Matorral } \\
\text { cerrado }\end{array}$ \\
\hline Suelo desnudo & 80 & 0 & 13 & 0 & 0 \\
\hline Estepa subarbustiva & 0 & 100 & 0 & 0 & 0 \\
\hline Estepa graminosa & 10 & 0 & 80 & 0 & 16 \\
\hline Matorral abierto & 10 & 0 & 0 & 85 & 9 \\
\hline Matorral cerrado & 0 & 0 & 7 & 15 & 75 \\
\hline
\end{tabular}

En la Figura 4 se muestran los cambios en la cubierta del suelo que se produjeron en los años estudiados, mostrándose los polígonos más representativos del área por unidad de paisaje.

El PCA mostró que en los gráficos de sedimentación a nivel de clase (Fig. 5 a, b y c) los primeros tres componentes explican más del $80 \%$ de la varianza de las métricas originales evaluadas, tanto para los cañadones, como para las pampas y los valles. Esto es coincidente con lo que se muestra en la Tabla 3, donde se refleja la varianza total explicada por cada uno de los componentes. En síntesis, prácticamente la totalidad de las métricas analizadas se explican a través de los componentes F1 y F2, a excepción de la métrica SPLIT, que se explica a través del componente F3, en las tres unidades de paisaje (Fig. 5 d, e y f). En el caso de las pampas y de los cañadones, el PD y SPLIT se explican a través del componente F3 y F4 respectivamente (Fig. 5 e y f). Es por esto que se seleccionaron las métricas PD, TE, DIVISION y MESH, que son las que mejor explican la variabilidad dentro de las métricas de clase analizadas. 


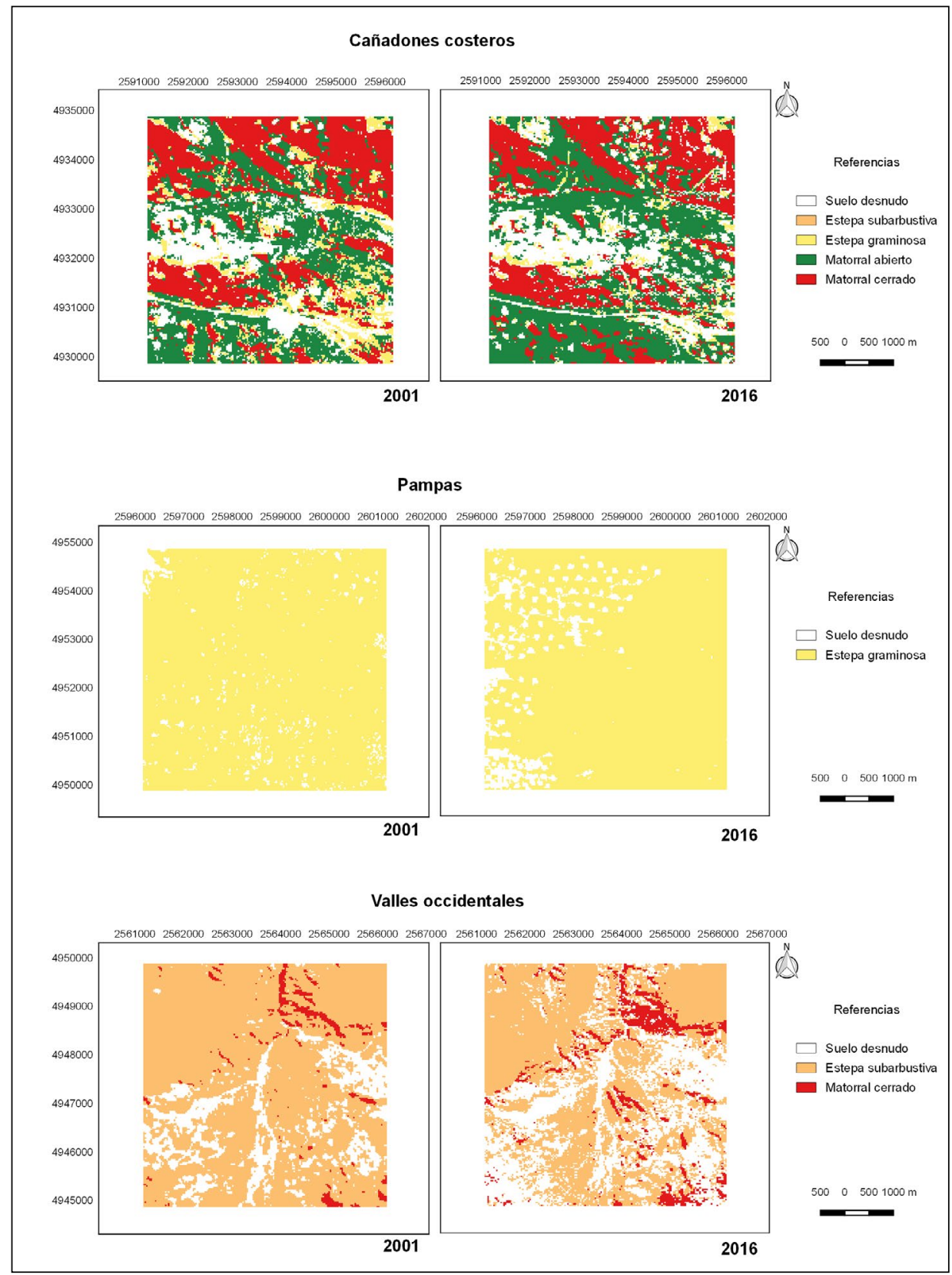

Figura 4. Clasificación supervisada de los polígonos más representativos en las unidades de paisajes para los años 2001 y 2016. 


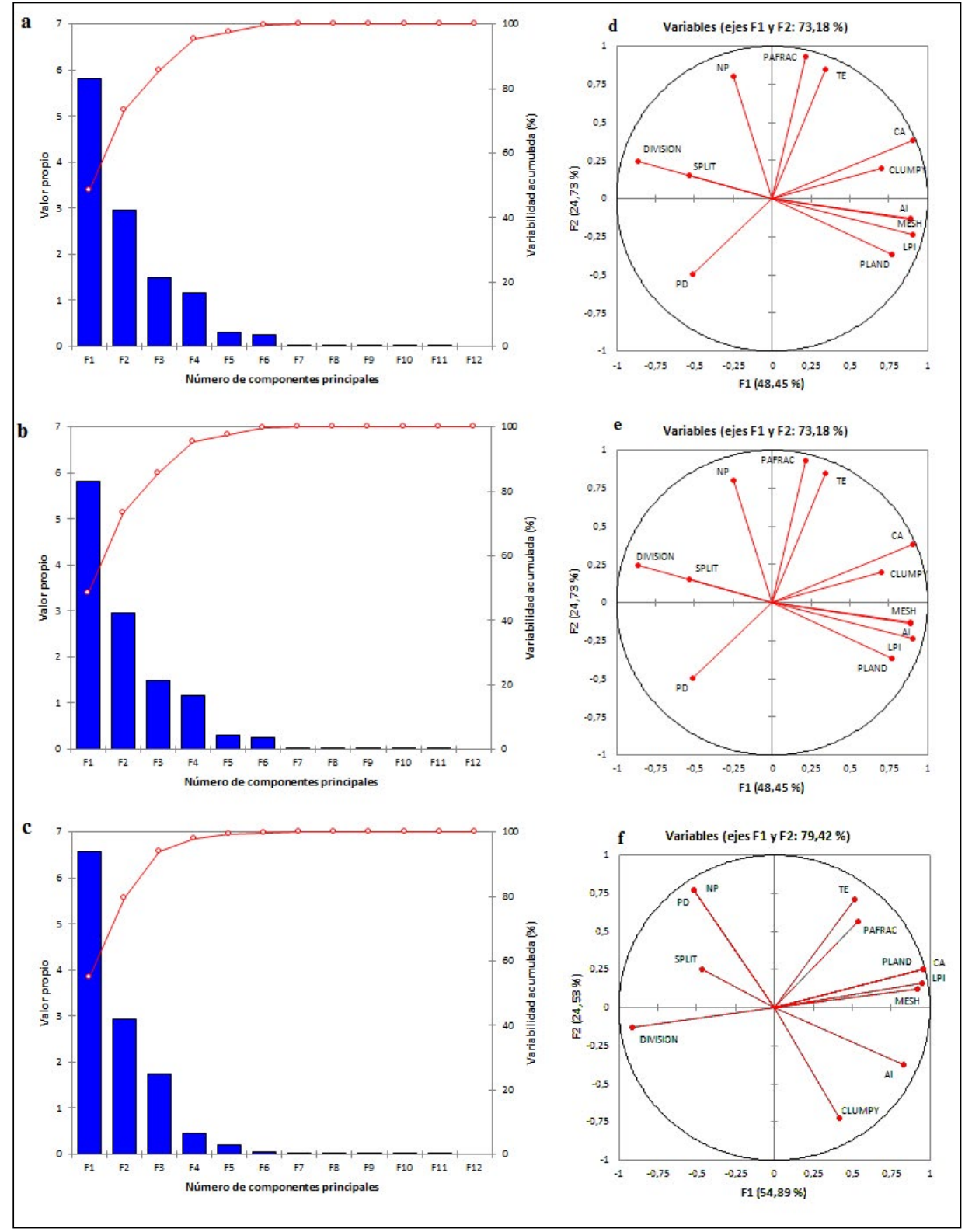

Figura 5. Análisis de componentes principales a nivel de clase en los cañadones costeros $(a, d)$, pampas $(b, e)$ y valles occidentales $(c, f)$ respectivamente. 
Tabla 3. Varianza total explicada a nivel de clase.

\begin{tabular}{lcccc}
\hline \multicolumn{5}{c}{ Cañadones costeros } \\
\hline Valor propio & $\mathrm{F} 1$ & $\mathrm{~F} 2$ & $\mathrm{~F} 3$ & $\mathrm{~F} 4$ \\
Variabilidad (\%) & 5,81 & 2,96 & 1,47 & 1,17 \\
\hline Pampas & 48,44 & 24,73 & 12,31 & 9,75 \\
\hline \multicolumn{5}{c}{} \\
Valor propio & $\mathrm{F} 1$ & $\mathrm{~F} 2$ & $\mathrm{~F} 3$ & $\mathrm{~F} 4$ \\
Variabilidad (\%) & 5,81 & 2,96 & 1,47 & 1,17 \\
\hline Valles occidentales & 48,44 & 24,73 & 12,31 & 9,75 \\
\hline & & & & \\
Valor propio & $\mathrm{F} 1$ & $\mathrm{~F} 2$ & $\mathrm{~F} 3$ & $\mathrm{~F} 4$ \\
Variabilidad (\%) & 6,58 & 2,94 & 1,75 & 0,45 \\
\hline
\end{tabular}

A nivel de paisaje, los gráficos de sedimentación muestran que los componentes F1 y F2 explican más del 89\% de la varianza total de las métricas analizadas (Fig. 6 g, h e y). La Tabla 4 muestra la variabilidad de los componentes con mayor variabilidad. Teniendo en cuenta el comportamiento de las métricas en los gráficos de componentes principales (Fig. 6 j, k y l) y los gráficos de sedimentación, se seleccionaron las métricas ED, CONTAG y MESH que son las que mejor explican la variabilidad total para las tres unidades de paisaje.

Tabla 4. Varianza total explicada a nivel de paisaje.

\begin{tabular}{lcccc}
\hline \multicolumn{5}{c}{ Cañadones costeros } \\
\hline & $\mathrm{F} 1$ & $\mathrm{~F} 2$ & $\mathrm{~F} 3$ & $\mathrm{~F} 4$ \\
Valor propio & 6,67 & 3,91 & 0,28 & 0,12 \\
Variabilidad (\%) & 60,71 & 35,56 & 2,55 & 1,16 \\
\hline Pampas & $\mathrm{F} 1$ & $\mathrm{~F} 2$ & $\mathrm{~F} 3$ & $\mathrm{~F} 4$ \\
\hline & 8,00 & 2,31 & 0,56 & 0,11 \\
Valor propio & 72,78 & 21,01 & 5,15 & 1,04 \\
Variabilidad (\%) & & & & \\
\hline Valles occidentales & & $\mathrm{F} 2$ & $\mathrm{~F} 3$ & $\mathrm{~F} 4$ \\
\hline & $\mathrm{F} 1$ & 1,54 & 1,05 & 0,06 \\
Valor propio & 8,33 & 14,02 & 9,60 & 0,62 \\
Variabilidad (\%) & 75,74 & & & \\
\hline
\end{tabular}




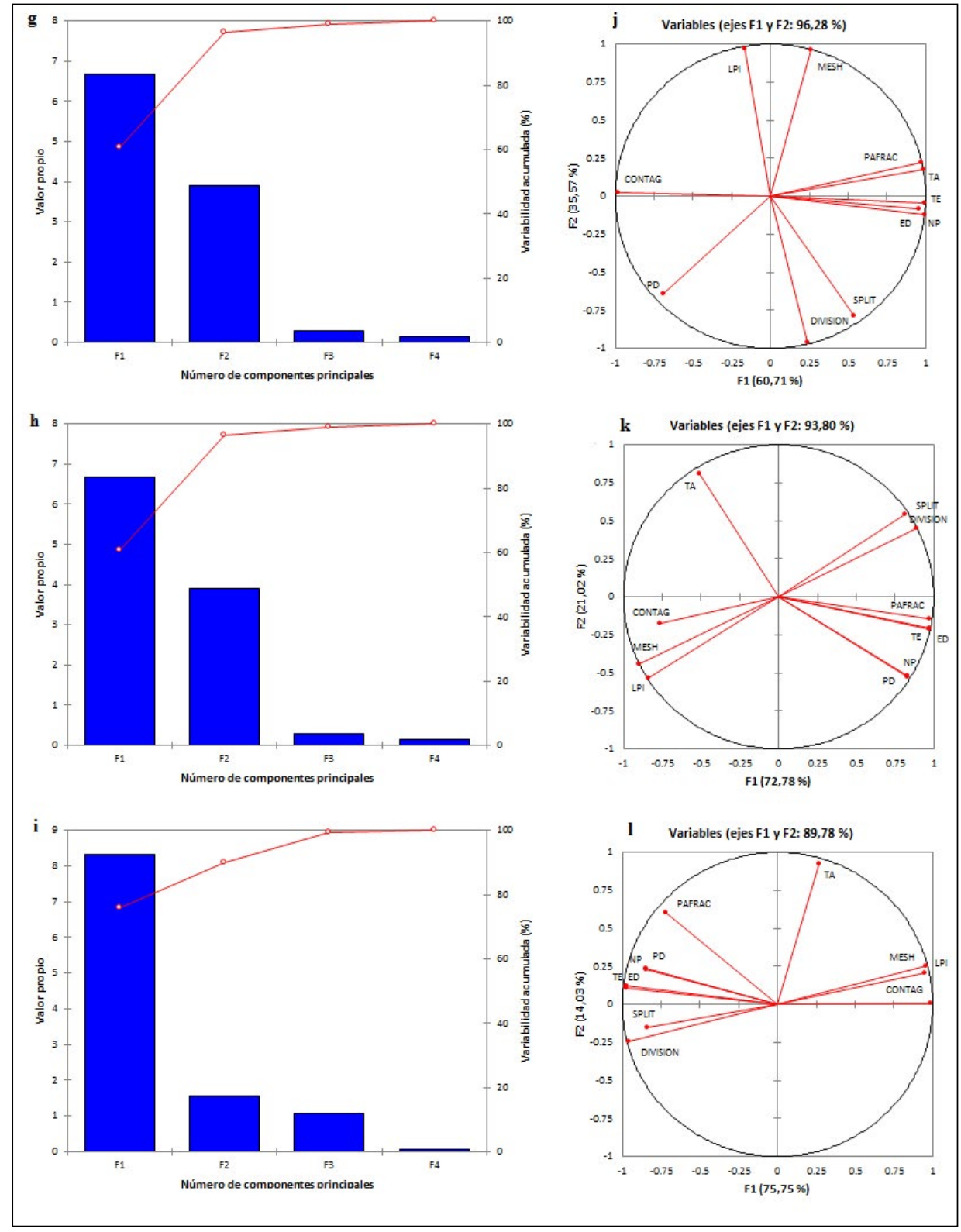

Figura 6. Análisis de componentes principales a nivel de paisaje en los cañadones costeros $(g, j)$, pampas $(h, k)$ y valles occidentales $(i, l)$ respectivamente.

Los resultados de las métricas seleccionadas muestran que la PD, TE, ED y DIVISION aumentaron, en las tres unidades de paisaje, entre 2001 y 2016. En cambio, el CONTAG disminuyó en el mismo periodo (Fig. 7). 
Buzzi et al.

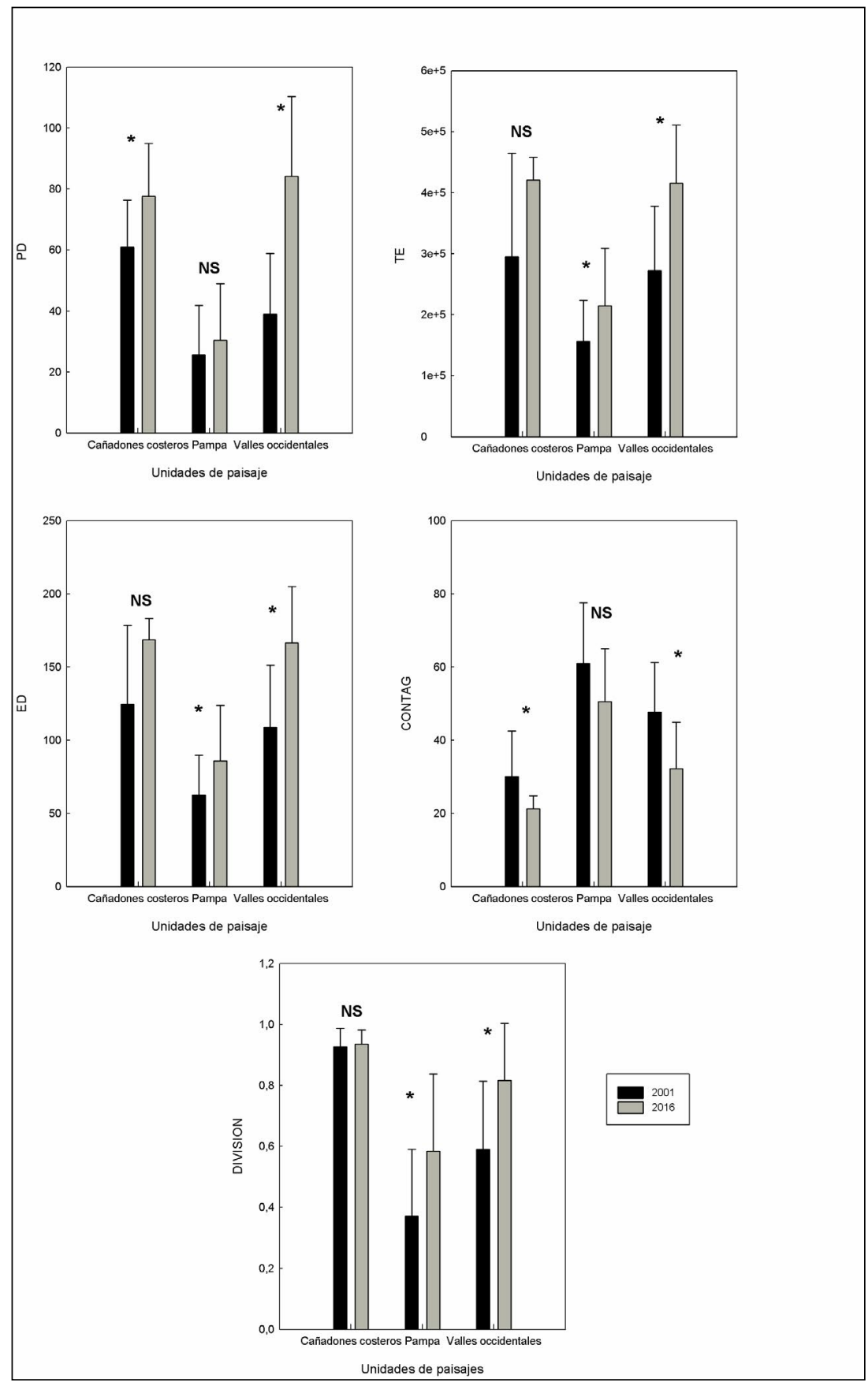

Figura 7. Métricas a nivel de paisaje. PD: densidad de parches (número de parches/100 ha), TE: borde total ( $m$ ), ED: densidad de borde ( $\mathrm{m} / \mathrm{ha}$ ), CONTAG: índice de contagio (\%), DIVISION: índice de división (proporción). * Valores significativos p<0,05. Las barras indican la desviación estándar. 


\subsection{Dinámica de las comunidades vegetales}

Entre 2001 y 2016, se observó un incremento significativo $(\mathrm{p}<0,05)$ del suelo desnudo en las pampas y en los valles occidentales (Fig. 8), y un retroceso de las comunidades vegetales dominantes: estepa graminosa en las primeras, y estepa subarbustiva en la segunda. En los cañadones, la comunidad vegetal matorral abierto aumentó en el periodo de tiempo analizado (Fig. 8).

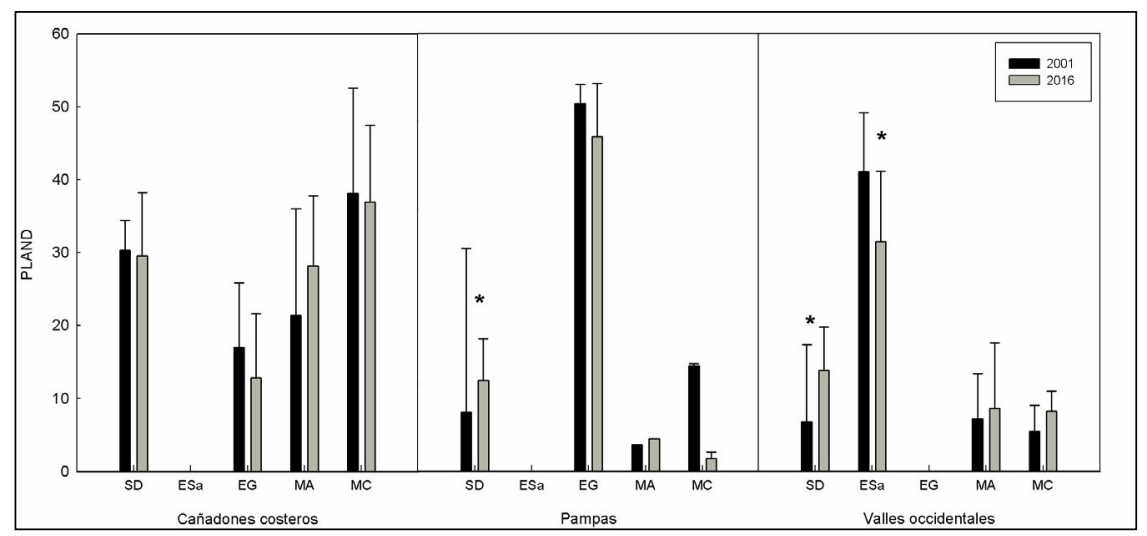

Figura 8. Índice PLAND a nivel de las comunidades vegetales de las unidades de paisaje. PLAND: porcentaje del paisaje (\%), Suelo desnudo (SD), estepa subarbustiva (ESa), estepa graminosa (EG), matorral abierto (MA) y matorral cerrado (MC). *Valores significativos $(p<0,05)$. Las barras indican la desviación estándar.

En los valles occidentales la PD de suelo desnudo y la comunidad vegetal dominante aumentaron significativamente $(\mathrm{p}<0,05)$. En los cañadones se incrementó la PD de los matorrales abiertos, entre 2001 y 2016 (Fig. 9).

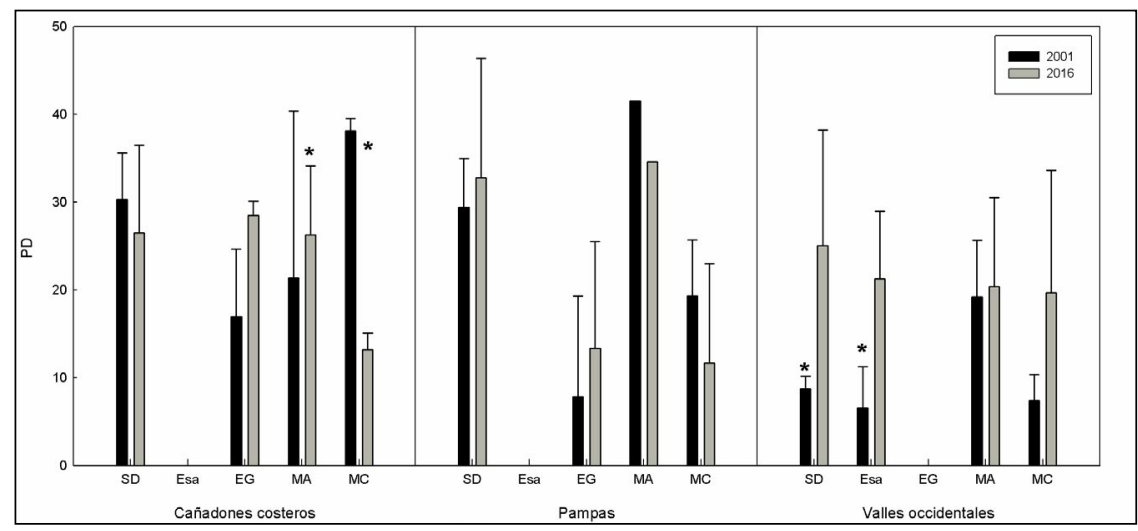

Figura 9. Índice PD a nivel de las comunidades vegetales de las unidades de paisaje. PD (número de parches cada 100 ha). Suelo desnudo (SD), estepa subarbustiva (ESa), estepa de gramineas (EG), matorral abierto (MA) y matorral cerrado (MC). "Valores significativos $(p<0,05)$. Las barras indican la desviación estándar. 


\subsection{Efecto de los disturbios}

La PD fue máxima en los sitios con explotación petrolera y ganadería ovina extensiva, mientras que el valor de la misma métrica del paisaje fue mínimo en los sitios no disturbados. Por ende, en los sitios afectados por una de los dos disturbios, la PD fue intermedia (Fig. 10 a). En los sitios sin disturbio el MESH fue máximo (MESH = 500 ha) y en los sitios con actividad petrolera, como único disturbio, fue mínima (MESH = 175,59 ha) (Fig. 10 b).
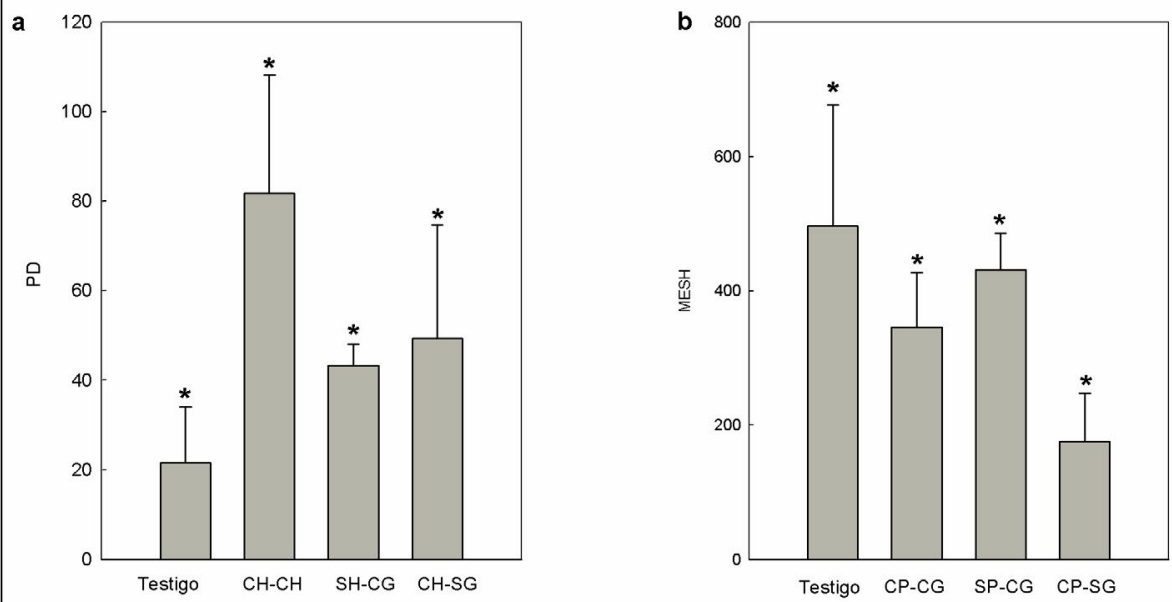

Figura 10. Índice PD en los sitios con y sin disturbio (a). Índice MESH en los sitios con y sin disturbio. PD: densidad de parches (número de parches cada 100 ha), MESH: tamaño efectivo de malla (ha). CH-CG: sitios con actividad petrolera y ganadera; $S H-C G$ : sitios sin actividad petrolera y con actividad ganadera; $\mathrm{CH}$-SG: sitios con actividad petrolera y sin actividad ganadera. "Valores significativos $(p<0,05)$. Las barras indican la desviación estándar.

\section{Discusión y conclusiones}

Los elevados coeficientes Kappa de las clasificaciones supervisadas obtenidas muestran que las mismas son operativas (Anderson et al., 1976) y pueden usarse para evaluar los cambios temporales de las comunidades vegetales, los cuales son producto de las interacciones entre procesos físicos, biológicos y sociales (Turner et al., 1989).

Los análisis multivariados se utilizan comúnmente para evitar la redundancia en las métricas de paisaje. Como antecedentes a este tipo de análisis se pueden citar los de Cushman et al., (2008) que utilizaron el PCA para identificar componentes independientes de la estructura del paisaje tanto a nivel de clase como a nivel de paisaje, o el trabajo propuesto por Plexida et al., (2014) que realizaron un análisis de redundancia para identificar las métricas que mejor explican el patrón del paisaje a diferentes escalas. 
En este trabajo se realizaron los PCA para determinar el paquete mínimo de métricas que permite representar la complejidad del paisaje y los cambios derivados del uso del suelo. Para esto se analizaron 12 métricas de clase: CA, PLAND, NP, PD, LPI, TE, PAFRAC, CLUMPY, DIVISION, MESH, SPLIT y AI; y 11 métricas de paisaje: TA, NP, PD, LPI, TE, ED, PAFRAC, CONTAG, DIVISION, MESH y SPLIT. Analizando tanto las métricas a nivel de clase (PLAND y PD) como a nivel de paisaje (TE, ED, CONTAG, DIVISION y MESH), se mostraron ser los mejores predictores de la dinámica de las comunidades vegetales y además son sensibles al efecto de los disturbios (actividad petrolera y ganadería ovina) en el área de estudio.

Los resultados obtenidos muestran que las cubiertas del suelo de la región árida y semiárida de la Patagonia argentina atraviesan un proceso de fragmentación en los últimos 15 años. Esta pérdida de conectividad visualizada a través del incremento de las métricas PD y ED, y al índice de DIVISION del área, muestra que se produjo un incremento y desagregación de los parches. El incremento de la fragmentación entre los años 2001 y 2016 fue más evidente en los valles occidentales que en las otras unidades de paisaje analizadas y esto significa que la fragmentación produce un efecto negativo más acentuado en las zonas donde la aridez es superior. En el área de estudio está presente un gradiente de aridez decreciente desde la parte central de la provincia de Chubut hacia la costa, o sea desde la biozona árida (valles occidentales) hacia la biozona semiárida (cañadones). La fragmentación, agravada por las condiciones de aridez, es coincidente con la tendencia presente en otras regiones que tienen como principal actividad económica la petrolera, donde los paisajes naturales se transforman en áreas degradadas y fragmentadas (Tang et al., 2008).

Las comunidades vegetales mostraron un cambio en la cubierta en el periodo estudiado. Parte de las comunidades dominantes de las pampas y en los valles occidentales (estepas de gramíneas y subarbustivas) fueron reemplazadas por suelo desnudo. En los valles occidentales los matorrales abiertos y cerrados aumentaron la cobertura evidenciando un proceso de "arbustización" o expansión de matorrales de plantas arbustivas en ambientes dominados por pastos u otras plantas herbáceas. Este proceso, mencionado por varios autores en la región (Bisigato y Bertiller, 1997; Aguiar y Sala, 1998; Graz, 2008; Escobar, 2011; Rueter, 2013), puede deberse a la ganadería ovina extensiva con cargas superiores a las recomendables. En muchos establecimientos ganaderos se produce una sobrecarga de ovinos, sobrestimando la capacidad de los ecosistemas patagónicos, lo que puede contribuir a acentuar tanto la "arbustización" como la desertificación (Celdran, 2010). El sobrepastoreo ovino produce, a nivel de paisaje, la reducción de la cubierta vegetal y el incremento de la erosión del suelo. Además, el pisoteo de los animales reduce la disponibilidad de agua y la fertilidad del suelo, produciendo cambios en la textura (Thornes, 1990). El sobrepastoreo ovino afecta fuertemente a la estructura y función de los ecosistemas mediante la selección de las especies comidas que son remplazadas por otras menos palatables (ej.: espinosas o con contenido elevado de metabolitos secundarios) y el pisoteo de los herbívoros que dispara mecanismos que propician el reemplazo de especies, la pérdida de suelo, la reducción de la producción de forraje y, por ende, la receptividad forrajera (Paruelo et al., 2005). Es importante, por lo tanto, realizar un análisis regional en el que se incluyan variables ambientales vinculadas a la intensidad 
del pastoreo, lo que permite predecir respuestas de la vegetación a los cambios ambientales naturales o introducidos por el hombre a escala global (Körner, 1994). Además, el incremento de la fragmentación observado en el área de estudio podría haberse agravado por la variación climática ocurrida en los últimos años, lo que condiciona fuertemente la producción forrajera (Andrade et al., 2010). Según los datos de precipitación de la

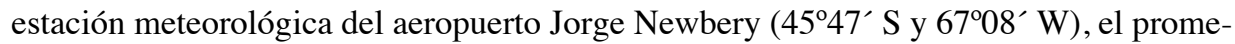
dio histórico de precipitaciones en el área es de 237 mm (1930-2016), y en el año 2016 fue de $164 \mathrm{~mm}$, siendo el más seco de la última década (Colombani, 2016). La sequía produce un efecto sinérgico con las actividades económicas de la región incrementando la desertificación.

Las principales fuerzas directrices del cambio en los patrones del paisaje en los ecosistemas áridos y semiáridos del sur de la Patagonia son la ganadería ovina extensiva (Soriano et al., 1980; Milchuna et al., 1988) y la explotación petrolera (Lovelace y Philips, 2014) UK. The metrics capture different aspects of vulnerability and highlight the importance La producción de petróleo de la Argentina en 2001 fue de $15.865 .100 \mathrm{~m}^{3}$ mientras que para el 2016 fue sustancialmente superior, $29.707 .501 \mathrm{~m}^{3}$, o sea casi el doble (Ministerio de Energía y Minería 2016). La cuenca del Golfo San Jorge fue la principal productora entre los dos años analizados, y los impactos sobre el medio ambiente son importantes, graves e irreversibles.

La explotación petrolera produce una remoción total de la cubierta vegetal en sitios puntuales, debido a la construcción de caminos que llevan a los pozos extractores de petróleo, líneas sísmicas, taludes, canteras e instalación de infraestructuras. El suelo original es reemplazado por materiales exógenos constituidos por bloques y áridos finos compactados con cemento calcáreo (Ciancio et al., 2013), que permiten el emplazamiento de instalaciones y el libre desplazamiento de vehículos de flota pesada. Estas alteraciones son notorias y claramente observables a través de las imágenes de satélite. Estas áreas son sensibles, desde el punto de vista ambiental, y contribuyen a la desertificación. Los cambios demográficos, socioeconómicos y tecnológicos de las últimas décadas han llevado a una presión excesiva sobre los recursos naturales, generando desertificación. La desertificación es un importante problema ambiental global y se estima que afecta al 65$70 \%$ de todas las áreas áridas, semiáridas y secas y subhúmedas del mundo (Reynolds et al., 2007). Particularmente, en la región patagónica afecta a 78,5 millones de hectáreas, con distinto grado de severidad: desertificación leve $(9,3 \%)$, moderada $(17,1 \%)$, moderada a severa $(35,4 \%)$, severa $(23,3 \%)$ y muy severa $(8,5 \%)$ (del Valle et al., 1998). Las principales causas de desertificación son la ganadería ovina extensiva (Bertiller et al., 1995; Perelman et al., 1997) y la explotación petrolera (Bertolami et al., 2010; Andrade, 2012; Peri et al., 2013). Diversos autores señalan que estas actividades han provocado o acentuado procesos de expansión de arbustos, fragmentación y pérdidas de biodiversidad (Schofield y Bucher, 1986; Roig, 1991; Corcuera y Bertonatti, 2000; Schlichter y Laclau, 2000; Pérez, 2012), coincidente con los resultados obtenidos en este trabajo.

En las últimas décadas el estudio de los procesos de fragmentación a escala de paisaje ha tenido una creciente importancia. Como hemos visto en este trabajo, la fragmentación se produce fundamentalmente por causas antropogénicas causadas, en este caso, 
por la actividad petrolera y la ganadería ovina extensiva, que producen modificaciones en el patrón y en la configuración del paisaje. Estas modificaciones alteran la dinámica natural de los procesos ecológicos y la distribución de las especies animales y vegetales. Esta evolución se asocia principalmente a cambios en la cubierta del suelo, que fueron fuertemente modificados en el siglo XX, favorecidos principalmente por el desarrollo industrial. Por lo tanto, la fragmentación del paisaje no solo ha sido estudiada en zonas áridas sino también en ambientes urbanos (Vardei et al., 2014), en ambientes costeros (Bi et al., 2011) y en áreas forestales (Shooshtari et al., 2018).

\section{Referencias}

Aguiar, M.R., Sala, O.E. 1998. Interaction among grasses, shrubs, and herbivores in Patagonian grass-shrub steppes. Ecología Austral 8, 201-210.

Alkemade, R., Reid, R.S., van den Berg, M., de Leeuw, J., Jeuken, M. 2013. Assessing the impacts of livestock production on biodiversity in rangeland ecosystems. Proceedings of the National Academy of Sciences 110 (52), 20900-20905. https://doi.org/10.1073/pnas.1011013108.

Anderson, J.F., Hardy, E.E., Roach J.T., Witmer, R.E. 1976. A land use and land cover classification system for use with remote sensor data. U.S. Geological Survey Professional Paper 964, U.S. Geological Survey, Washington, DC, 28 pp.

Andrade, L. 2012. Producción y ambiente en la Meseta Central de Santa Cruz, Patagonia austral en Argentina: desencadenantes e impacto de la desertificación. Ambiente y Desarrollo 16 (30), 73-92.

Ares, J., del Valle, H., Bisigato, A. 2003. Detection of process-related changes in plant patterns at extended spatial scales during early dryland desertification. Global Change Biology 9, 16431659. https://doi.org/10.1046/j.1365-2486.2003.00690.x.

Beeskow, A.M., del Valle, H., Rostagno C.M. 1987. Los Sistemas Fisiográficos de la Región Árida y Semiárida de la Provincia del Chubut. SECYT. Puerto Madryn, Chubut, Argentina, 143 pp.

Bertiller, M.B., Elissalde, N.O., Rostagno, C.M., Defossé, G.E. 1995. Environmental pattern and plant distribution along a precipitation gradient in western Patagonia. Journal of Arid Environments 29, 85-97.

Bertolami,M.A.,Mendos, M.G., Rueter, B.L.,González,L.V., Benítez, M.E. 2010.Los geosistemas y el NDVI como referentes de la variación de la vegetación asociada a causas ambientales en Patagonia Central. Revista de la Asociación Argentina de Ecología de Paisajes 1(1), 15-26.

Bi, X., Wang, B., Lu, Q. 2011. Fragmentation effects of oil wells and roads on the Yellow River Delta, North China. Ocean Coastal Management 54, 256-264. https://doi.org/10.1016/j. ocecoaman.2010.12.005.

Bisigato, A.J., Bertiller, M.B. 1997. Grazing effects on patchy dryland vegetation in northern Patagonia. Journal of Arid Environments 36, 639-653.

Buzai G.D., Mendoza, N. 2004. El espacio geográfico como estructura de mosaicos. Gerencia Ambiental 11 (104), 172-176.

Buzzi, M.A., Bertolami, M., Rueter, B. 2013. Delimitación de unidades de paisaje en Patagonia central. Revista de la Asociación Argentina de Ecología de Paisajes 4 (2), 211-218.

Buzzi, M.A., Rueter, B.L., Ghermandi, L. 2017. Múltiples índices espectrales para predecir la variabilidad de atributos estructurales y funcionales en zonas áridas. Ecología Austral 27, 55-62.

Chávez, P.S. 1996. Image-based atmospheric corrections-revisited and improved. Image-Based Atmospheric Corrections - Revisited and Improved. Photogrammetric engineering and remote sensing 62(9), 1025-1035.

Chuvieco, E. 2010. Teledetección ambiental. La observación de la tierra desde el espacio, Ariel, Barcelona, España, 590 pp. 
Ciancio, M.E., Tchilinguirian, P., Zuleta, G.A., Castro, M.L., Pérez, A.A., 2012. Rehabilitación de estepas arbustivas del monte austral en explanadas petroleras. Evaluación de la técnica de escarificado II: suelo y microtopografía. En: R.D. Perez, A.E., Rovere, M.E. Rodriguez Araujo (Eds.), Rehabilitación y Restauración en la Diagonal Árida de la Argentina. Editorial de la Universidad Nacional del Comahue (EDUCO), Neuquén.

Congedo, L. 2016. Semi-Automatic Classification Plugin Documentation. http://doi.org/10.13140/ RG.2.2.29474.02242/1.

Corcuera J., Bertonatti D. 2000. Situación Ambiental Argentina 2000. Fundación Vida Silvestre Argentina. Buenos Aires, $391 \mathrm{pp}$.

Cushman, S.A., McGarigal, K., Neel, M.C. 2008. Parsimony in landscape metrics: Strength, universality, and consistency. Ecological Indicators 8 (5), 691-703. http://10.1016/j.ecolind. 2007.12.002.

del Valle, H.F., Elissalde, N.O., Gagliardini, D.A., Milovich, J. 1998. Status of desertification in the Patagonian region: assessment and mapping from satellite imagery. Arid Soil Research and Rehabilitation 12 (2), 95-121.

Eldridge, D.J., Poore, A.G., Ruiz-Colmenero, M., Letnic, M., Soliveres S. 2016. Ecosystem structure, function and composition in rangelands are negatively affected by livestock grazing. Ecological Applications 26, 1273-1283. https://doi.org/10.1890/15-1234.

Escobar, L.I. 2011. Efecto de clausuras de ganado en la recuperación de la vegetación en el Parque Nacional Laguna Blanca. Tesis de licenciatura para acceder al título de Lic. en Ciencias Biológicas. Universidad Nacional del Comahue. Bariloche.

Fahrig, L., Baudry, J., Brotons, L., Burel, F.G., Crist, T.O., Fuller, R.J., Sirami, C., Siriwardena, G.M., Martin, J.L. 2011. Functional landscape heterogeneity and animal biodiversity in agricultural landscapes. Ecology letters 14, 101-112. https://doi.org/10.1111/j.14610248.2010.01559.x.

Fischer, J., Lindenmayer, D.B. 2006. Beyond fragmentation: the continuum model for fauna research and conservation in human-modified landscapes. Oikos 112 (2), 473-480. https:// doi.org/10.1111/j.0030-1299.2006.14148.x.

Fischer, J., Lindenmayer, D.B. 2007. Landscape modification and habitat fragmentation: a synthesis. Global Ecology and Biogeography 16, 265-280. https://doi.org/10.1111/j.14668238.2007.00287.x.

Fleischner, T.L. 1994. Ecological costs of livestock grazing in western North America. Conservation biology 8 (3), 629-644. https://doi.org/10.1046/j.1523-1739.1994. 08030629.x.

Foody, G.M. 2002. Status of land cover classification accuracy assessment. Remote Sensing of Environment 80, 185-201. https://doi.org/10.1016/S0034-4257(01)00295-4.

Forman, R.T.T., Godron, M. 1981. Patches and Structural Components for a Landscape. BioScience $31(10), 733-740$.

Forman, R.T.T. 1995. Land Mosaics. The Ecology of Landscapes and Regions. Cambridge University Press, Nueva York, 632 pp.

Graz, P., 2008. The woody weed encroachment puzzle: gathering pieces. Ecohydrology 1(4), 340348. https://doi.org/10:1002/eco.28.

Harrison, S., Davies, K.F., Safford, H.D., Viers, J.H. 2006. Beta diversity and the scale-dependence of the productivity-diversity relationship: a test in the Californian serpentine flora. Journal of Ecology 94, 110-117. https://doi.org/10.1111/j.1365-2745.2005.01078.x.

Herrera, L., Laterra, P. 2007. Relaciones entre la riqueza y composición florística con el tamaño de fragmentos de pastizales en la Pampa Austral, Argentina. En: S. Matteucci,(Eds.), Panorama de la Ecología de Paisajes en Argentina y en Países de Sudamericanos. Ediciones INTA. Buenos Aires, pp. 387-396. 
Herrera, L., Laterra, P. 2011. Relative influence of size, conectivity and disturbance history on plant species richness and assemblages in fragmented grasslands. Applied Vegetation Science 14, 181-188.

Huang, B., Zhang, L., Wu, B. 2009. Spatiotemporal analysis of rural-urban land conversion. International Journal of Geographical Information Science 23 (3), 379-398. http://doi.org/ $10.1080 / 13658810802119685$.

INDEC 2010. Censo Nacional de Población, Hogares y Viviendas. Disponible en: https://www. indec.gov.ar/nivel4_default.asp?id_tema_1=2\&id_tema_2=41\&id_tema_3=135 (Fecha de acceso 15/06/18).

Keles, S., Sivrikaya, F., Çakır, G., Köse, S. 2008. Urbanization and forest cover change un regional directorate of Trabzon forestry from 1975 to 2000 using Landsat data. Environmental Monitoring and Assessment 140, 1-14. https://doi.org/10.1007/s10661-007-9845-5.

Körner, C. 1994. Scaling from species to vegetation: the usefulness of functional groups. En: Biodiversity and ecosystem function. Springer, Berlin, Heidelberg, pp. 117-140.

León, R., Bran, D., Collantes, M., Paruelo, J., Soriano, A., 1998. Grandes unidades de vegetación de la Patagonia Extrandina. Ecología Austral 8, 125-144.

Li, H., Wu, J. 2004. Use and misuse of landscape indices. Landscape Ecology 19, 389-399. https:// doi.org/10.1023/B:LAND.0000030441.15628.d6.

Li, X., Yang, Q., Liu, X. 2008. Discovering and evaluating urban signatures for simulating compact development using cellular automata. Landscape and Urban Planning 86, 177186.

Losos, J.B., Ricklefs, R.E. 2010. The theory of island biogeography revisited. Princeton University Press, Princeton, NJ.

Lovelace, R.,Philips, I. 2014. The "oil vulnerability" of commuter patterns: A case study from Yorkshire and the Humber, UK. Geoforum 51, 169-182. https://doi.org/10.1016/j.geoforum.2013.11.005.

Lu, D., Batistella, M., Moran, E., de Miranda, E.E. 2008. A comparative study of Landsat TM and SPOT HRG images for vegetation classification in the Brazilian Amazon. Photogrammetric Engineering \& Remote Sensing 74 (3), 311-321. https://doi.org/10.14358/PERS.74.3.311.

MacArthur, R.H., Wilson, E.O. 1967. The Theory of Island Biogeography. Princeton University, Princeton, USA.

Maestre, F.T., Cortina, J. 2004. Insights into ecosystem composition and function in a sequence of degraded semiarid steppes. Restoration Ecology 12, 494-502.

Manning, A.D., Lindenmayer, D.B., Nix, H.A. 2004. Continua and Umwelt: novel perspectives on viewing landscapes. Oikos 104 (3), 621-628. https://doi.org/10.1111/j.00301299.2004.12813.x.

Martínez del Castillo, E., García-Martin, A., Longares Aladrén, L. 2015. Evaluation of forest cover change using remote sensing techniques and landscape metrics in Moncayo Natural Park (Spain). Applied Geography 62, 247-255. https://doi.org/10.1016/j. apgeog.2015.05.002.

McGarigal, K. 2015. FRAGSTATS 4.2 Help. Amherst. Online available at http://www.umass. edu/landeco/research/fragstats/documents/fragstats_documents.html. (Fecha de acceso 15 de febrero del 2017).

Milchuna, D.G., Sala, O.E., Lauenroth, W.K. 1988. A generalized model of the effects of grazing by large herbivores on grassland community structure. American Naturalist 132, 87-106.

Ministerio de Energía y Minería de la República Argentina, 2013. Online available at https://www. argentina.gob.ar/energia/hidrocarburos/produccion-de-petroleo-y-gas (Fecha de acceso 03 de marzo de 2018).

Mohammady, M., Moradi, H.R., Zeinivand, H., Temme, A.J.A.M. 2015. A comparison of supervised, unsupervised and synthetic land use classification methods in the north of Iran. 
International Journal of Environmental Science and Technology 12, 1515-1526. https://doi. org/10.1007/s13762-014-0728-3.

Olaya, V. 2014. Sistemas de Información Geográfica, Bubok, Madrid. Disponible en: http://www. icog.es/TyT/files/Libro_SIG.pdf (Fecha de acceso: 15/06/18).

Paruelo, J., Golluscio, R., Guerschman, J.P., Cesa, A., Jouve, V., Garbulsky, M. 2004. Regional scale relationships between ecosystem structure and functioning: the case of the Patagonian Steppes. Global Ecology and Biogeography 13, 385-395.

Paruelo, J., Guerscham, J., Verón, S. 2005. Expansión agrícola y cambios en el uso del suelo. Ciencia Hoy 15 (87), 1-7.

Paruelo, J., Aguiar, M.R. 2003. El caso de desertificación en Patagonia. Ciencia Hoy 13 (77), 48-59.

Perelman, S.B., León, R.J.C., Bussacca, J.P. 1997. Floristic changes related to grazing intensity in a Patagonian shrub steppe. Ecography 20, 400-406.

Pérez, R.D., Rovere, A.E., Rodríguez Araujo, M.E. (Eds.) 2012. Rehabilitación y Restauración en la Diagonal Árida de la Argentina. Editorial de la Universidad Nacional del Comahue (Eds.), Neuquén, pp.518.

Peri, P.L., Lencinas, M.V., Martínez Pastur, G., Wardell-Johnson, G.W. 2013. Diversity Patterns in the Steppe of Argentina Southern Patagonia: environmental drivers and impact. En: M.B. Morales Prieto, J. Traba Diaz (Eds.), Steppe Ecosystems, Nova Science Publishers, pp. 73-95.

Pincheira-Ulbrich, J., Rau, J.R., Peña Cortés, F. 2009. Patch size and shape and their relationship with tree and shrub species richness. International Journal of Experimental Botany 78, 121-128.

Plexida, S.G., Sfougaris, A.I., Ispikoudis, I.P., Papanastasis, V.P. 2014 . Selecting landscape metrics as indicators of spatial heterogeneity - a comparison among Greek landscapes. International Journal of Applied Earth Observation Geoinformation 26, 26-35.

Reynolds, J.F., Smith, D.M.S., Lambin, E.F., Turner, B.L., Mortimore, M., Batterbury, S.P., HuberSannwald, E. 2007. Global desertification: building a science for dryland development. Science, 316 (5826), 847-851.

Richards, J.A., Jia, X. 2006. Interpretation of Hyperspectral Image Data. En: Remote Sensing Digital Image Analysis. Springer, Berlin, Heidelberg, pp. 359-388. https://doi.org/10.1007/3540-29711-1_13.

Roig, V.G. 1991. Desertification and distribution of mammals in the southern cone of South America. En: M.A. Mares, D. Schmidly (Eds.), Latin American Mammalogy. History, Biodiversity and Conservation, Norman: University of Oklahoma Press, pp. 239-279.

Rueter, B.L. 2013. Análisis Estructural y Funcional de las Comunidades Vegetales de los Cañadones Costeros del Distrito del Golfo San Jorge. Su variación temporal. Tesis doctoral. Universidad Nacional de la Patagonia San Juan Bosco. Comodoro Rivadavia.

Schlichter, T., Laclau, P. 2000. Valoración económica de la desertificación en Patagonia y de algunas alternativas de desarrollo basadas en la conservación de los Recursos Naturales. 272289. En: J. Corcuera, D. Bertonatti, (Eds.), Situación Ambiental Argentina 2000. Fundación Vida Silvestre Argentina. Buenos Aires.

Schofield, C.J., Bucher, E.H. 1986. Industrial contributions to desertification in South America. Trends in Ecology and Evolution 1, 78-80.

Soriano, A., Sala, O.E., Leon, R.J.C. 1980. Vegetación actual y vegetación potencial en el pastizal de coirón amargo (Stipa spp.) del SW de Chubut. Boletín de la Sociedad Argentina de Botánica 19 (1-2), 309-314.

Syrbe, R.U., Walz, U. 2012. Spatial indicators for the assessment of ecosystem ser- vices: providing, benefiting and connecting areas and landscape metrics. Ecological Indicators 21, 80-88. http://doi.org/10.1016/j.ecolind.2012.02.013. 
Tang, J., Wang, L., Yao, Z. 2008. Analyses of urban landscape dynamics using multi-temporal satellite images: a comparison of two petroleum-oriented cities. Landscape Urban Planning 87, 269-278. https://doi.org/10.1016/j.landurbplan.2008.06.011.

Thornes, J.B. 1990. The interaction of erosional and vegetational dynamics in land degradation: Spatial outcomes. En: J.B. Thornes (Eds.), Vegetation and erosion: Processes and environments, Wiley \& Sons, New York, pp. 41-54.

Turner, M.G., O’Neill, R.V., Gardner, R.H., Milne, B.T. 1989. Effects of changing spatial scale on the analysis of landscape pattern. Landscape Ecology 3, 153-162.

Uuemaa, E., Mander, Ü., Marja, R. 2013. Trends in the use of landscape spatial metrics as landscape indicators: a review. Ecological Indicators 28, 100-106. https://doi.org/ 10.1016/j. ecolind 2012.07.018.

Valdés, A., García, D. 2009. Applying a continua landscape approach to evaluate plant response to fragmentation: Primula vulgaris in the Cantabrian mountains. International Association for Vegetation Science 12, 504-515.

Wang, J., Rich, P.M., Price, K.P., Kettle, W.D. 2005. Relations between NDVI, grassland production, and crop yield in the Central Great Plains. Geocarto International 20, 1-7.

Vardei, H.M., Salmanmahiny, A., Monavari, S.M., Zarkesh, M.M.K. 2014. Cumulative effects of developed road network on woodland - a landscape approach. Environmental monitoring and assessment 186(11), 7335-7347. https://doi.org/10.1007/s10661-014-3930-3. 